\title{
AGRICULTURA FAMILIAR, HABITUS E ACESSO À TERRA
}

Luís Felipe Perdigão de Castro ${ }^{\mathrm{i}}$

Sumário: Introdução. $1 \mathrm{O}$ Acesso à terra como direito humano e fundamental. 2 A ideia de desenvolvimento na agricultura brasileira: panorama histórico. 3 As formas de agir e viver do agricultor familiar como elementos valorativos para um "outro desenvolvimento". 4 Agricultura familiar, habitus e valorações sobre a terra. Conclusão. Referências.

\section{Resumo}

O presente artigo discute a dinâmica histórica e cultural do rural brasileiro, enfatizando as formas de agir e viver do agricultor familiar. Investigam-se fatores de caráter social e cultural altamente específicos dos agricultores familiares e suas relações com perspectivas de desenvolvimento agrícola alternativas às propostas originárias da Revolução Verde. O pano de fundo é o acesso à terra como direito constitucional fundamental.

Palavras-chave: Agricultura familiar. Habitus. Progresso. Modernização. Valores

\footnotetext{
${ }^{1}$ Doutorando em Ciências Sociais, pelo Centro de Estudos Comparados sobre as Américas, da Universidade de Brasília (CEPPAC/UnB). Mestre em Agronegócios (Universidade de Brasília). Bacharel em Direito (Universidade Federal de Ouro Preto). Advogado (OAB/DF). Professor de Direito no Centro Universitário de Desenvolvimento do Centro Oeste (UNIDESC) e nas Faculdades Integradas da União Educacional do Planalto Central (FACIPLAC). Ex-assessor de Juiz na Comarca de Luziânia/GO - lfperdigao@gmail.com.
} 


\begin{abstract}
This article discusses the historical and cultural dynamics of the brazilian rural. The ways of acting and living of the brazilian family farmer are investigated as highly specific social and cultural characters. These elements are analyzed as an alternative agricultural development. The backdrop is access to land as a fundamental constitutional right.
\end{abstract}

Keywords: Brazilian family farmer. Habitus. Progress. Modernization. Values.

\section{INTRODUÇÃO}

$\mathrm{O}$ presente trabalho parte da ideia de que a "modernização da agricultura" é, reflexivamente, produto da organização dos recursos agrícolas, do cálculo de racionalidade e planejamento econômico, mas, sobretudo, decorrência de elementos históricos altamente específicos, determinantes da construção social do uso e da apropriação de recursos privados e públicos.

No caso do Brasil, essa trajetória é marcada pelo período pós-1965, em que os anseios de "modernização da agricultura" foram profundamente vinculados à ideia de progresso.

A implantação da Revolução Verde, por meio de um amplo programa de crédito e outros incentivos governamentais, consolidou a concepção de progresso no campo como produção baseada na combinação intensiva de tecnologia, capitais e informações. Nesse contexto, a agricultura familiar foi associada à ideia de atraso, de passado e, mesmo, de pobreza.

Por esse viés, o presente artigo discute de que forma os valores inseridos na agricultura familiar possibilitam um desenvolvimento social e econômico divergente, ou pelo menos diferen- te, da proposta da Revolução Verde e seus atuais desdobramentos.

No tocante ao direito constitucional, essa discussão tem por pano de fundo a função social da propriedade e a dignidade da pessoa humana (artigo $1^{\circ}$, inciso III, da CF/88) que legitimam, do ponto de vista jurídico e social, o esforço para constituir a terra como "um lugar de vida e de trabalho, capaz de guardar a memória da família e de reproduzi-la para as gerações posteriores"1.

Para tanto, apresentamos um breve panorama sobre a ideia de desenvolvimento na agricultura brasileira para, em seguida, discutir questões valorativas ligadas às formas de agir e de viver do agricultor familiar. $\mathrm{O}$ objetivo é analisar como se manifesta o papel da agricultura familiar para a mudança nas relações humanas, econômicas e sociais do campo e da sociedade, enfatizando reflexamente a diversidade cultural e social preconizada na Constituição Federal de 1988.

\section{O ACESSO À TERRA COMO DIREITO HU- MANO E FUNDAMENTAL}

Os direitos fundamentais, enquanto conjunto institucionalizado de direitos e garantias do ser humano, têm por finalidade básica garantir o respeito à dignidade humana, por meio da proteção contra o arbítrio do poder estatal e o estabelecimento de condições mínimas de vida e desenvolvimento da personalidade. Assim, são direitos ligados à plena realização das "condições mínimas de vida e desenvolvimento da personalidade humana"2.

Nesse entendimento, ainda que de cunho predominantemente didático, a doutrina diferencia "direitos do homem", "direitos humanos" e "direitos fundamentais". Os direitos do homem são de cunho jusnaturalista, ainda não positivados. Direitos humanos, por sua vez, dizem respeito à positivação de preceitos no âmbito do direito internacional. Os direitos fundamentais são preceitos protegidos internamente pelo direito constitucional de cada Estado. ${ }^{3}$

\footnotetext{
${ }^{1}$ WANDERLEY, M. N. B. Raízes históricas do campesinato brasileiro. In: TEDESCO, João Carlos (Org.). Agricultura familiar: realidades e perspectivas. 1. ed. Passo Fundo, RS: Universidade de Passo Fundo, 1999. p. 11.

${ }^{2}$ MORAES, A. Direitos humanos fundamentais: teoria geral, comentários aos arts. $1^{\circ}$ a $5^{\circ}$ da Constituição da República Federativa do Brasil, doutrina e jurisprudência. 6. ed. São Paulo: Atlas, 2005. p. 21.

${ }^{3}$ SARLET, I. W. A eficácia dos direitos fundamentais. 7. ed. rev. atual. e ampl. Porto Alegre: Livraria do Advogado, 2007. p. 36.
} 
O acesso à terra rural é um direito humano que se destaca como necessário à realização plena de uma série de outros direitos. Nesse sentido, o acesso à terra é um direito humano aglutinador e viabilizador de outros preceitos constitucionais básicos, como a vida e a dignidade humana. Para melhor compreensão, tomemos por exemplo a relação entre os direitos de acesso à terra e de alimentação adequada.

Alimentar-se adequadamente é um direito humano com bases jurídicas na Declaração Universal dos Direitos Humanos e recepcionado na Constituição Federal de 1988. Detalhado no Comentário Geral 12, enfatiza-se que o direito de alimentar-se não ocorre somente por sistemas eficientes de distribuição, processamento e venda de alimentos, mas também pelo acesso à terra. Dentre os principais dispositivos constitucionais que colocam o acesso à terra rural como direito humano e fundamental está o princípio da função social da propriedade.

O artigo 186 da ordem constitucional em vigor especifica que a função social é cumprida quando a propriedade rural atende, simultaneamente, aos seguintes requisitos:

I - aproveitamento racional e adequado;

II - utilização adequada dos recursos naturais disponíveis e preservação do meio ambiente;

III - observância das disposições que regulam as relações de trabalho;

IV - exploração que favoreça o bem-estar dos proprietários e dos trabalhadores. ${ }^{4}$

Além disso, a Constituição Federal reconheceu o direito de acesso à terra quando se referiu a povos indígenas e outras comunidades tradicionais, mediante direitos especiais sobre territórios. Tais direitos estão assegurados em tratados internacionais como a Convenção 169 da Organização Internacional do Trabalho (OIT), aprovada pelo Decreto Legislativo n. 143, de junho de 2002, o qual determina que o Estado deverá reconhecer aos povos interessados os direitos de posse sobre as terras que tradicionalmente ocupam. Esses dispositivos preconizam medidas que garantam o direito dos povos interessados em utilizar terras que não estejam exclusivamente ocupadas por eles, mas as quais, tradicionalmente, tenham tido acesso para suas atividades de subsistência.

Por esse viés, a Constituição Federal, em seu artigo 231, assegura aos índios o direito sobre as terras que tradicionalmente ocupam. Ao garantir este direito fica estabelecido que a ocupação originária precede e prevalece sobre qualquer outra posse, porque é o direito ao território que traz também a marca da necessidade cultural, religiosa e política, vinculado ao direito de autodeterminação dos povos.

Além dos povos indígenas, as comunidades quilombolas também possuem o direito constitucionalmente garantido ao território, previsto na Constituição Federal no art. 68 das Disposições Transitórias, que define: "Aos remanescentes das comunidades dos quilombos que estejam ocupando suas terras é reconhecida a propriedade definitiva, devendo o Estado emitir-lhes os títulos definitivos". ${ }^{5}$

Embora a Constituição Federal não tenha dado à agricultura familiar um tratamento específico no tocante ao acesso à terra, este direito está profundamente relacionado à categoria social.

Nesse sentido, a agricultura familiar é o principal ator social para a garantia do direito humano à alimentação adequada, este previsto desde 2010 na Constituição da República. Os agricultores familiares produzem cerca de $70 \%$ dos alimentos que são consumidos no planeta. No Brasil, esse segmento produz $87 \%$ da mandioca, $70 \%$ do feijão, $46 \%$ do milho, $38 \%$ do café, $34 \%$ do arroz, $21 \%$ do trigo, $60 \%$ do leite, $59 \%$ do rebanho suíno, $50 \%$ das aves e $30 \%$ dos bovinos. Toda essa capacidade produtiva ocorre em meio a uma realidade social em que os agricultores possuem pouca ou nenhuma terra. ${ }^{6}$

\footnotetext{
${ }^{4}$ BRASIL. Constituição da República Federativa do Brasil de 1988. Disponível em: <http://www.planalto.gov.br/ccivil_03/constituicao/ConstituicaoCompilado.htm>. Acesso em: 19 de jan. 2016.

${ }^{5}$ BRASIL. Constituição da República Federativa do Brasil de 1988. Disponível em: <http://www.planalto.gov.br/ccivil_03/constituicao/ConstituicaoCompilado.htm>. Acesso em: 19 de jan. 2016.

${ }^{6}$ CASTRO, L. F. P.; SAUER, S. A problemática e as condicionantes dos arrendamentos rurais na agricultura familiar. Anais... 50 Congresso da SOBER, Espírito Santo, Vitória, 2012. p. 09.
} 
Contudo, a importância de se discutir o direito de acesso à terra como direito humano, no âmbito da agricultura familiar, não se liga apenas à segurança alimentar, mas a novas formas de se propor o desenvolvimento, na medida em que essa categoria social evidencia formas de viver e de agir peculiares, presentes na interação do homem com a produção agrícola e com o meio ambiente. A agricultura familiar acessa e difunde formas de saber, de organização do trabalho, de cultivo de sementes e de tecnologias não ligadas aos modelos homogeneizadores de produção. Dessa forma, o diálogo entre acesso à terra e agricultura familiar traz a lume a questão da luta por terra como espaço de reivindicação de direitos que transcendem a propriedade fundiária, mas se traduzem em demandas por infraestrutura, serviços públicos e autonomia, com desdobramentos práticos sobre a memória da família, emprego produtivo, geração de renda e combate à fome.

\section{A IDEIA DE DESENVOLVIMENTO NA AGRICULTURA BRASILEIRA: PANORAMA HISTÓRICO}

A combinação de mão de obra escrava, primeiramente indígena e depois africana, aplicada ao cultivo monocultor da cana-de-açúcar, constituiu o primeiro ciclo econômico do Brasil-Colônia e a origem de "uma estrutura agrária socialmente excludente, predatória de recursos naturais e concentradora do acesso à terra"'

A concepção de desenvolvimento mercantilista do Estado Moderno português - cuja lógica básica foi promover o exclusivo comercial $^{8}$ para garantir o equilíbrio da balança comercial lusa e a acumulação bulionista - iniciou o ciclo de aproveitamento econômico das terras brasilei- ras, que, ao longo de séculos, mantém-se dentro de pactos de poder político e social, nos quais "a grande propriedade, dominante em toda a sua História, se impôs como modelo socialmente reconhecido". ${ }^{9}$ Em tal cenário, a agricultura familiar ocupou um "lugar secundário e subalterno na sociedade brasileira. Quando comparado ao campesinato de outros países, foi historicamente um setor 'bloqueado', impossibilitado de desenvolver suas potencialidades" enquanto forma social específica. ${ }^{10}$

Partindo de tais precursores históricos, sem ignorar as peculiaridades de cada período, mas lançando um olhar panorâmico sobre o trajeto da institucionalidade estatal, o processo de "consolidação da tradição autoritária do Estado brasileiro" constituiu uma "barreira à construção da ação coletiva" na luta por direitos, inclusive o de acesso à terra. Em épocas mais recentes, ao findar da Ditadura Militar (anos 80 do século XX), a implementação desses direitos, conquistados por ocasião da Constituição de 1988, foi dificultada no início do período neoliberal em toda a América Latina, nos anos 1990. ${ }^{11}$

Em síntese, do Período Colonial à República contemporânea, o quadro de especificidades no campo brasileiro pode ser caracterizado pela incorporação de novas terras somada à concentração fundiária. Em termos numéricos, o índice de Gini em 1992, que era de 0,826, apresentou decréscimo de apenas 0,010 para o ano de $2003^{12}$, mostrando a persistência e a atualidade do caráter excludente do modelo brasileiro.

Esse modelo é fruto do desenvolvimento pensado a partir do atrelamento da estrutura econômica à organização político-social, em condições originalmente mercantil-coloniais, que se reatualizam e se mesclam a novos elementos. $\mathrm{Na}$

\footnotetext{
${ }^{7}$ WANDERLEY, M. N. B. Reencontro com o Nordeste: itinerários de pesquisa e construção do campo intelectual dos estudos rurais. Estudos de Sociologia, Recife, v. S, n. 1, p. 1-132, 1999. Disponível em: <http://www.revista.ufpe.br/revsocio/index.php/revista/article/view/306>. Acesso em: 19 jan. 2016. p. 52 .

${ }^{8}$ FURTADO, C. Formação econômica do Brasil. São Paulo: Companhia das Letras, 2007. p.11.

${ }^{9}$ WANDERLEY, M. N. B. Raízes históricas do campesinato brasileiro. In: MOTA, D. M. da; TAVARES, E. D.; IVO, W. M. P. de (Org.). Agricultura familiar em debate. Aracaju,SE: EMBRAPA-CPATC, 1997. p. 08.

${ }^{10}$ WANDERLEY, M. N. B. Raizes históricas do campesinato brasileiro. In: MOTA, D. M. da; TAVARES, E. D.; IVO, W. M. P. de (Org.). Agricultura familiar em debate, p. 08.

${ }^{11}$ BALESTRO, M. V.; MARINHO, D. N. C.; WALTER, M. I. Seguro-desemprego no Brasil: a possibilidade de combinar proteção social e melhor funcionamento do mercado de trabalho. Sociedade e Estado. Brasília: UnB. Impresso, 2011. p. 203.

${ }^{12}$ GIRARDI, E. P. Proposição teóricometodológica de uma cartografia geográfica crítica e sua aplicação no desenvolvimento do Atlas da Questão Agrária Brasileira. Tese (Doutorado em Geografia) - Faculdade de Ciências e Tecnologia, Universidade Estadual Paulista, Presidente Prudente. 2008. p. 204.
} 
reinvenção do velho, o uso da terra e seus recursos sob uma lógica fortemente capitalista (guardadas as devidas diferenças de tempo e espaço históricos) trazem consigo a essência do modelo mercantil-colonial que, de forma excludente e concentradora, está focada nas regras de como e o que produzir para exportar, compondo o conjunto de questões estruturais que barram outro modelo de desenvolvimento para o país ${ }^{13}$.

Exemplo dessa reatualização é a Revolução Verde, como projeto imposto ao conjunto da sociedade, sob o argumento de que seria a portadora do progresso para todos, subordinando a agricultura à indústria, pelo complexo agroindustrial. Sob a égide da Revolução Verde, a agricultura brasileira deveria cumprir algumas funções para o projeto de desenvolvimento industrial, tais como liberar mão de obra, fornecer alimentos e matérias-primas para aumento da oferta e diminuição dos preços na indústria, transferir capital e gerar divisas, aumentar o incremento tecnológico e a produtividade com apoio do arcabouço institucional do crédito rural, pesquisa agrícola, preços mínimos e extensão rural. ${ }^{14}$

Essa concepção, no fim da década de 1990, sofreu questionamentos. O modelo de desenvolvimento neoliberal, imposto por órgãos internacionais, como o Banco Mundial e o Fundo Monetário Internacional, buscou solucionar os problemas causados pelo capitalismo por meio das próprias regras capitalistas. Contudo, as críticas a tal paradigma de Estado passariam a indicar outra via, a do desenvolvimento intolerável aos olhos do capitalismo, já que este modelo contraria suas regras. ${ }^{15}$ Esse momento de questionamento também foi decisivo para que se evidenciasse que as democracias desenvolvidas não precisariam seguir um único modelo econômico - o modelo de mercado norte-americano, reforçando as peculiaridades de outros modelos: o modelo social europeu, o modelo desenvolvimentista asiático ou japonês e o modelo misto de capitalismo latino-americano. ${ }^{16}$

Esses modelos, porém, não se consolidaram pacificamente no Brasil, mas em meio a lutas de resistência de diversas categorias sociais, a exemplo dos "Agricultores Familiares". Esses agricultores lutam e resistem por meio de ocupações, mobilização e organização social em entidades e, principalmente, pela reprodução de suas formas de agir e de viver no campo. A criação de assentamentos rurais e a própria recriação do campesinato são manifestações de luta por terra, como lugar de vida e dignidade. ${ }^{17}$

Tais especificidades nos mostram a existência de diferentes capacidades de resistência e adaptação de categorias sociais, frente às condições do campo brasileiro. As formas de resistência da "Agricultura Familiar" trazem consigo respostas à imposição de modelos de desenvolvimento baseados nos valores da Revolução Verde e, como formas de agir e de viver, representam novas perspectivas de desenvolvimento para o rural e para o nacional.

Nesse contexto, como "resultado da capacidade de iniciativa, adaptação e resistência da própria população do campo"18 aos processos locais e mais gerais da sociedade, os agricultores familiares foram reconhecidos e vêm firmando-se como atores sociais responsáveis pela produção da maior parte dos alimentos consumidos no Brasil. ${ }^{19}$ Embora não se possa falar em um projeto de desenvolvimento "exclusivo" da

\footnotetext{
${ }^{13}$ GIRARDI, E. P. Proposição teóricometodológica de uma cartografia geográfica crítica e sua aplicação no desenvolvimento do Atlas da Questão Agrária Brasileira, p. 119.

${ }^{14}$ KAGEYAMA, A et al. O novo padrão agrícola brasileiro: do complexo rural aos complexos agroindustriais. In: DELGADO, G.C.; GASQUES, J.G.; VILLA VERDE, C.M. (Orgs.) Agricultura e políticas públicas. Brasília: IPEA, 1990. p. 113-223.

${ }^{15}$ GÓMEZ, J. R. M. Desenvolvimento em (des)construção: narrativas escalares sobre desenvolvimento territorial rural. Presidente Prudente, 2006. Tese (Doutorado em Geografia) - Faculdade de Ciências e Tecnologia, Universidade Estadual Paulista, 2006. p. 397-398.

${ }^{16}$.GIRARDI, E. P. Atlas da Questão Agrária Brasileira. Disponível em: <http://www2.fct.unesp.br/nera/atlas/questao_agraria.htm>. Acesso em: 19 jan. 2016.

${ }^{17}$ CASTRO, L. F. P.; SAUER, S. A problemática e as condicionantes dos arrendamentos rurais na agricultura familiar. Anais... 50 ${ }^{\circ}$ Congresso da SOBER, Espírito Santo: Vitória, 2012. p. 03.

${ }^{18}$ WANDERLEY, M. N. B. O mundo rural brasileiro: acesso a bens e serviços e integração campo-cidade. Estudos Sociedade e Agricultura e Sociedade. Rio de Janeiro, UFRJ, v.17, n. 1, 2009. p. 61.

${ }^{19}$ CASTRO, L. F. P. Dimensões e lógicas do arrendamento rural na agricultura familiar. 2013. Dissertação (Mestrado em Agronegócios) - Universidade de Brasília, Brasília, 2013. p. 11.
} 
"Agricultura Familiar", é possível identificar nas peculiaridades culturais do agricultor familiar, elementos implícitos à sua forma de agir e de viver, que apontam para formas sustentáveis de desenvolvimento social e econômico, tanto no rural, quanto no nacional.

Trata-se de um processo histórico reflexivo, pois a "agricultura familiar que se reproduz nas sociedades modernas deve adaptar-se a um contexto socioeconômico próprio destas sociedades, que a obriga a realizar modificações importantes em sua forma de produzir e em sua vida social tradicionais" ${ }^{20}$. A compreensão dessa dimensão de desenvolvimento diferenciado exige, contudo, que se avalie o ambiente institucional em que essa categoria se insere e a forma com que seu sistema de valores se relaciona com ele.

Calha frisar que o termo agricultura familiar, neste trabalho, recupera o pensamento de Wanderley $^{21}$, para quem a conceituação assume ares de novidade, designando conceitos já enraizados na sociedade brasileira, como o tradicional camponês, o agricultor de subsistência e o pequeno produtor rural, e incorpora, conceitualmente, os desafios da modernidade. A agricultura familiar, que se reproduz nas sociedades modernas, deve adaptar-se a um contexto socioeconômico próprio dessas sociedades, as quais levam a modificações importantes nas formas de vida social tradicionais.

Essas transformações não significam, contudo, uma ruptura total e definitiva com as formas anteriores, devendo o agricultor familiar moderno adaptar-se às novas exigências da sociedade, sem desvincular-se das tradições camponesas. ${ }^{22}$

Segundo Sauer ${ }^{23}$, na luta pela terra, enquanto resistência aos processos de dominação e exclusão, termos como agricultura familiar e agronegócio surgem enquanto conceitos-síntese ou mais que simples categorias empíricas, à medida que teriam uma construção, apropriação e uso voltados para a expressão de identidades sociais. Nesse contexto, a agricultura familiar pode ser caracterizada a partir dos seguintes elementos:

a) a gestão da unidade produtiva e os investimentos nela realizados são feitos por indivíduos que mantém entre si laços de sangue ou casamento; b) a maior parte do trabalho é igualmente fornecida pelos membros da família; c) a propriedade dos meios de produção (embora nem sempre da terra) pertence à família e é em seu interior que se realiza sua transmissão em caso de falecimento ou aposentadoria dos responsáveis pela unidade produtiva ${ }^{24}$.

Do ponto de vista legal, com um viés mais operacional, a Lei n. 11.326, de 24 de julho de 2006, definiu o agricultor familiar como aquele:

[...] que pratica atividades no meio rural, atendendo, simultaneamente, aos seguintes requisitos:

I - não detenha, a qualquer título, área maior do que 4 (quatro) módulos fiscais;

II - utilize predominantemente mão-de-obra da própria família nas atividades econômicas do seu estabelecimento ou empreendimento;

III - tenha renda familiar predominantemente originada de atividades econômicas vinculadas ao próprio estabelecimento ou empreendimento; IV - dirija seu estabelecimento ou empreendimento com sua família. ${ }^{25}$

Embora essas definições pareçam bem delimitadas, o termo agricultura familiar se consolida e se difunde nos diferentes setores da sociedade, como um "guarda-chuva conceitual que abriga grande número de situações", em contraposição à agricultura patronal, tendo como ponto focal da polarização os tipos de mão de obra e de gestão empregados. Assim, as unidades de produção familiar seriam "formas de conexão, de disjunção e de conjunção", sistemas de "procedimentos e de

\footnotetext{
${ }^{20}$ WANDERLEY, M. N. B. Agricultura familiar e campesinato: rupturas e continuidades. In: (Org.). O mundo rural como espaço de vida: reflexões sobre a propriedade da terra, agricultura familiar e ruralidade. Porto Alegre. Ed. da UFRGS, 2009. p. 43-44.

${ }^{21}$ WANDERLEY, M. N. B. O agricultor familiar no Brasil: um ator social da construção do futuro. Revista Agriculturas - Experiências em Agroecologia. Rio de Janeiro, AS-PTA, p. 33-45, 2009. p. 41-43.

${ }_{22}^{2}$ WANDERLEY, M. N. B. Raizes históricas do campesinato brasileiro. In: TEDESCO, João Carlos (Org.). Agricultura familiar: realidades e perspectivas, p. 02 .

${ }^{23}$ SAUER, S. Agricultura familiar versus agronegócio: a dinâmica sociopolítica do campo brasileiro. Brasília, DF: Embrapa Informação Tecnológica, 2008. p. 67.

${ }^{24}$ INSTITUTO NACIONAL DE COLONIZAÇ̃̃O E REFORMA AGRÁRIA/FOOD AND AGRICULTURE ORGANIZATION OF THE UNITED NATIONS. Perfil da Agricultura Familiar no Brasil: dossiê estatístico. MDA: Brasília, 1996. p. 04.

${ }^{25}$ BRASIL. Lei n. 11.326, de 24 de julho de 2006. Estabelece as diretrizes para a formulação da Política Nacional da Agricultura Familiar e Empreendimentos Familiares Rurais. Disponível em: <http://www.planalto.gov.br/ccivil_03/_ato2004-2006/2006/lei/l11326.htm>. Acesso em: 19 jan. 2016.
} 
estratégias e não uma estrutura dada, à qual aos indivíduos só cabe a própria modelação" 26 .

Para o objeto desta pesquisa, interessa investigar abordagens que dão espaço à reflexão sobre a complexidade da lógica intrínseca à agricultura familiar, "apontando para a importância das afiliações socioculturais dos grupos sociais, isto é, seu modo de ver as coisas" 27 .

\section{AS FORMAS DE AGIR E VIVER DO AGRI- CULTOR FAMILIAR COMO ELEMENTOS VALORATIVOS PARA UM “OUTRO DESEN- VOLVIMENTO"}

A modernização da agricultura brasileira foi uma imposição baseada no argumento de um projeto pretensamente portador do progresso ${ }^{28}$. Esse processo garantiu "à classe média a inserção no circuito global de consumo", reforçando o uso da terra e seus recursos sob uma lógica fortemente capitalista, à medida que se tornaram centrais "as regras de como e o que produzir para exportar" 29 .

Embora essa lógica pareça evidente, suas formas assumem, sob as condições modernas, aspectos diferentes de todas as versões anteriores e, portanto, há que se considerar variedades do capitalismo ao conceituar as diferenças entre os tipos modernos de capitalismo. ${ }^{30}$ Essa é uma importante especificidade para compreender, de forma mais global e comparativa, as forças que regeram e regem a dinâmica da modernização da agricultura.

Por esse viés, a modernização do campo no Brasil se desenvolveu no contexto de uma economia de mercado hierárquica, na qual o ambiente institucional foi determinado pela ausência de relações de emprego de longo prazo, baixos ní- veis de sindicalização, poucos investimentos em qualificação profissional e uma grande distância de poder entre os trabalhadores e suas representações. O elevado grau de hierarquia ocorre nas relações entre trabalhadores e empregadores, assim como nas relações entre os próprios empregados. Somam-se a essas características "o elevado grau de informalidade, a alta rotatividade e a alta taxa de desemprego aberto" 31 .

Em termos comparativos, se as economias de mercado liberais enfatizaram os processos de coordenação guiados pelos mecanismos de mercado (os EUA são o paradigma), as economias de mercado coordenado lograram o êxito da concertação entre seus agentes, como ocorreu na Alemanha. Porém, no caso do Brasil, vigoram estruturas conflitantes de capitalismo, como versões intermediárias dos tipos ideais ${ }^{32}$.

Essa variedade de capitalismo, com princípio alocativo nas hierarquias, foi, entre nós, um importante fator que reforçou o campo como o espaço em que as instituições geram mais assimetrias socioeconômicas que complementaridades funcionais. Ou seja, por um lado, foi capaz de viabilizar a inserção global nos mercados, aumento da produtividade e competitividade econômica por meio do agronegócio, mas, por outro, bloqueou a resolução de problemas históricos como as desigualdades sociais de acesso à terra, a insegurança alimentar, a insuficiência de serviços públicos no campo, a deficiência de infraestrutura física em áreas mais pobres, a baixa captação de crédito por agricultores familiares, confluindo, em última análise, para um processo crônico de concentração de riquezas. Dessa forma, "a ideia de desenvolvimento econômico é um simples mito", que possibilita desviar as aten-

\footnotetext{
${ }^{26}$ NEVES, D. P. Agricultura familiar: questões metodológicas. Revista Reforma Agrária. Campinas,SP, v. 25, n, 2, p. 21-37. 1995. p. 34.

${ }^{27}$ CHALITA, M. A. N. Agricultura familiar na citricultura paulista: a reconstituição da trajetória de um conceito. Anais... XLIII Congresso da Sociedade Brasileira de Economia e Sociologia Rural - Instituições, eficiência, gestão e contratos no sistema agroindustrial. São Paulo, Ribeirão Preto, 2005. p. 09. ${ }^{28}$ KAGEYAMA, A et al. O novo padrão agrícola brasileiro: do complexo rural aos complexos agroindustriais. In: DELGADO, G. C; GASQUES, J. G.; VILLA VERDE, C. M. (Org.). Agricultura e políticas públicas. Brasília: IPEA, 1990. p. 113-223.

${ }^{29}$ GIRARDI, E. P. Atlas da Questão Agrária Brasileira. Disponível em: <http://www2.fct.unesp.br/nera/atlas/questao_agraria.htm>. Acesso em: 19 jan. 2016.

${ }^{30}$ HALL, P. A.; GINGERICH, D. W. Varieties of capitalism and institutional complementarities in the macroeconomy: an empirical analysis. Cologne: Max Planck Institute for the Study of Societies MPIFG Discussion Paper, 2004. Disponível em: <http://www.mpifg.de/pu/mpifg_dp/dp04-5.pdf>. Acesso em: 20 jan. 2016. p. 08-10.

${ }^{31}$ CHAHAD, J. P. Z. Flexibilidade no mercado de trabalho, proteção aos trabalhadores e treinamento vocacional de força de trabalho: a experiência de América Latina e perspectivas (Análise do caso brasileiro). Documento de Proyecto da CEPAL. Santiago: Naciones Unidas, 2009. p. 212.

${ }^{32}$ BALESTRO, M. V.; MARINHO, D. N. C.; WALTER, M. I. Seguro-desemprego no Brasil: a possibilidade de combinar proteção social e melhor funcionamento do mercado de trabalho. Sociedade e Estado. Brasília: UnB. Impresso, 2011. p. 11.
} 


\subsection{SOCIOLOGIA CONSTITUCIONAL}

ções da tarefa básica de identificação das necessidades fundamentais da coletividade, para concentrá-las em objetivos abstratos como são os investimentos, as exportações e o crescimento" ${ }^{33}$.

A interação dessas condicionantes com fatores políticos e sociais favoreceu a associação entre progresso e escala da propriedade, segundo a qual apenas os grandes proprietários puderam beneficiar-se das somas consideráveis de recursos públicos a ele destinados, reforçando a tendência histórica de concentração da terra. Tais assimetrias condicionaram o apropriamento do termo agronegócio como conceito-síntese da eficiência, eficácia, tecnologia, capitais e informações do setor produtivo rural comprometido com a modernização conservadora, identificando a agricultura familiar como conceito-síntese do atraso, da força braçal e da ineficiência. Esse modelo de desenvolvimento dicotômico favoreceu a produtividade, sem distribuição de capital, tecnologia e informação, em desfavor da agricultura familiar.

Assim, considerando as mazelas de nossa variedade de capitalismo, as dificuldades de conciliar êxito econômico e social, bem como a fragilidade do "enforcement", temos que o ambiente institucional em que os agricultores familiares se inserem é o de uma modernidade que reproduziu formas tradicionais de dominação e de exclusão social. De um lado, restringiu-se aos trabalhadores não proprietários o acesso à terra, de outro, tornou-se o crédito e a tecnologia inalcançáveis aos pequenos proprietários descapitalizados ou em descapitalização. O resultado disso é que, em 2004, a população rural representava $17,1 \%$ do total, mas $31,5 \%$ do total dos pobres estavam na área rural, evidenciando "relações de força profundamente assimétricas que são assim reproduzidas" 34

Ao mesmo tempo em que propicia concentra- ção de terras, crédito e tecnologia, esse ambiente institucional retroalimenta formas de resistência e de luta através do "esforço para constituir um 'território' familiar, um lugar de vida e de trabalho, capaz de guardar a memória da família e de reproduzi-la para as gerações posteriores" 35 . Existem condições de pressão social intensas, haja vista que no campo brasileiro, onde vivem apenas $18,8 \%$ da população, foi registrado um êxodo rural de 4,2 milhões de pessoas no período 1991-2000 e a extinção de 1,5 milhões de postos de trabalho no campo no período 1996 $2006 .{ }^{36}$

Essas tensões provocam formas de resistência na forma de luta pela terra que se traduzem ora como movimentos de ocupação para acesso ao recurso produtivo, ora como forma de resistência cultural. A ideia de desenvolvimento da agricultura brasileira foi baseada em um projeto de modernização econômica e tecnológica, por meio da capitalização do latifúndio com recursos públicos. Isso representou a sistemática exclusão do agricultor familiar do acesso à terra e seus recursos, não somente pela construção de pactos políticos excludentes, direcionados a capitalistas urbanos, oligarquias e setores patronais capitalizados. Tais categorias, além de historicamente empoderadas, possuem valorações adequadas à "aliança entre o capital e a terra", ao passo que o agricultor familiar está culturalmente inserido em outra lógica de aproveitamento do capital e da terra, no qual a renda e o lucro são elementos componentes e não norteadores de suas decisões.

Nesse cenário, a Constituição Federal de 1988 é um importante marco para os discursos e as lutas das diversas categorias sociais relacionadas à disputa por terra. Com a Letra Magna de 1988, o princípio da função social assumiu novas significações. Ou seja, o debate sobre a questão agrária passou a considerar, do ponto de vista jurídico,

\footnotetext{
${ }^{33}$ FURTADO, C. O mito do desenvolvimento econômico. São Paulo: Círculo do Livro, 1974. p. 75.

${ }^{34}$ WANDERLEY, M. N. B. O mundo rural brasileiro: acesso a bens e serviços e integração campo-cidade. Estudos Sociedade e Agricultura. Rio de JaneiroRJ, UFRJ, v.17, n.1, 2009. p. 71.

${ }^{35}$ WANDERLEY, M. N. B. Raízes históricas do campesinato brasileiro. In: TEDESCO, João Carlos (Org.). Agricultura familiar: realidades e perspectivas, p. 11.

${ }^{36}$ INSTITUTO BRASILEIRO DE GEOGRAFIA E ESTATÍSTICA. Séries Estatísticas \& Séries Históricas. Censos Agropecuários (1920 a 1995/96). Rio de Janeiro, RJ: IBGE. 2013. Disponível em: <http:www.ibge.gov.br/series_estatisticas/subtema.php?idsubtema=100:. Acesso em: 15 set. 2014; INSTITUTO BRASILEIRO DE GEOGRAFIA E ESTATÍSTICA. Censo Agropecuário 2006: Brasil, Grandes Regiões e Unidades da Federação. Rio de Janeiro, RJ: IBGE. 2007. Disponível em: <http://ibge.gov.br/home/estatistica/economia/agropecuaria/censoagro/2006_segunda_apuracao/default.shtm>. Acesso em: 15 set. 2014
} 
que a função social da terra tem por fundamento a cidadania e a dignidade da pessoa humana.

A Constituição Federal de 1988 deu importante passo na institucionalização dos direitos fundamentais no campo na medida em que reconheceu que o acesso legítimo à terra ocorre nos estritos limites da utilização adequada e "não de modo cego e mecânico" ${ }^{37}$. Nessa linha, a posse agrária é que passou a legitimar a propriedade agrária em sede constitucional ${ }^{38}$.

Posto nesse ambiente institucional, o agricultor familiar avalia as condições de produção para além de instrumentais jurídicos ou econômicos, típicos da agricultura capitalista, incorporando "uma diversidade de situações específicas e particulares" 39 . É por essa especificidade que se manifesta o papel revolucionário da agricultura familiar para a mudança nas relações humanas, econômicas e sociais do campo e da sociedade. Isto é, sua forma de agir e de vivenciar representa uma alternativa ao desenvolvimento baseado no binômio capital-terra, voltando-se para uma via de desenvolvimento sustentável e instrumentalizado por uma reforma agrária de feição especialmente modernizadora, não somente do ponto de vista econômico, mas como superação de relações de dominação. ${ }^{40}$

Há, portanto, uma racionalidade intrínseca ao agricultor familiar, que ultrapassa o pacto capital-terra, criando novas visões sobre o que seja desenvolvimento econômico, social e político. A percepção das vantagens ou desvantagens do ambiente institucional está submetida a um arranjo de cosmovisões ${ }^{41}$ que se insere em uma unidade e que, do ponto de vista operacional e cultural, é ao mesmo tempo estrutura de produção, de consumo e de reprodução sociocultural. Ideias como progresso, desenvolvimento e modernização estão vinculadas à produção combinada de valores de uso e de mercadorias, objetivando, para além da renda, do lucro ou da comercialização, a reprodução social das cosmovisões. $^{42}$

Essa peculiaridade na forma de lidar com recursos e promover o desenvolvimento não passa ao largo da Constituição Federal de 1988. Elementos como artes, memória coletiva e repasse de saberes se relacionam ao conceito antropológico de cultura, à dignidade da pessoa humana e ao terreno comumente reverenciado como cultura pelo direito brasileiro, devendo ser considerado que: "cultura para o mundo jurídico é a produção humana juridicamente protegida, relacionada às artes, à memória coletiva e ao repasse de saberes, e vinculada ao ideal de aprimoramento, visando à dignidade da espécie como um todo, e de cada um dos indivíduos"43.

Nesse sentido, a orbe constitucional alcança a agricultura familiar como espaço de manifestação cultural peculiar e legitimamente protegida. A família, como proprietária dos meios de produção, trabalho na terra, valores e tradições (patrimônio sociocultural) em torno da e para a família ${ }^{44}$ cria valorações de base cultural acerca da relação de trabalho, do grupamento afetivo e da visão da terra como lar. Noutras palavras, todo processo de desenvolvimento do agricultor familiar se baseia na reflexão e no exercício de opções econômicas e políticas profundamente orientadas por fatores de caráter social e cultural altamente específicos. ${ }^{45}$

A renda ou o lucro seria aspecto componente das decisões, mas não orientadora delas, conforme atestam inúmeros estudos de caso. A "integração ao mercado e a garantia do consumo" - fundamental para a constituição do "pa-

\footnotetext{
${ }^{37}$ COMPARATO, F. K. Direito e deveres em matéria de propriedade. In: STROZAKE, J. J. (Org.). A questão agrária e a justiça. São Paulo: RT, 2000. p. 146. ${ }^{38}$ LIMA, R. A. M. Direito agrário. Rio de Janeiro: Renovar, 1994. p. 89. No mesmo sentido: MIRANDA, A. G. O instituto jurídico da posse agrária. Belém: Cejup, 1992. p. 51.

${ }^{39}$ WANDERLEY, M. N. B. Raízes históricas do campesinato brasileiro. In: TEDESCO, João Carlos (Org.). Agricultura familiar: realidade e perspectivas, p. 02 .

${ }^{40}$ SAUER, S. Terra e modernidade: a reinvenção do campo brasileiro. São Paulo: Expressão Popular, 2010. p. 35-50.

${ }^{41}$ Neste caso, é o modo pelo qual o agricultor familiar vê ou interpreta a realidade. A palavra alemã é weltanschau-ung, que significa um 'mundo e uma visão da vida', ou 'um paradigma'. É a estrutura por meio da qual a pessoa entende os dados da vida. (GEISLER, 2002).

${ }^{42}$ CASTRO, L. F. P. Dimensões e lógicas do arrendamento rural na agricultura familiar, p. 76.

${ }^{43}$ CUNHA FILHO, F. H. Direitos culturais como direitos fundamentais no ordenamento jurídico brasileiro. Brasília: Brasília Jurídica, 2000. p.28

${ }^{44}$ TEDESCO, J. C. Agricultura familiar: realidades e perspectivas. Passo Fundo, RS: Ed. da UPF, 2001, p. 149-155.

${ }^{45}$ CASTRO, L. F. P. Dimensões e lógicas do arrendamento rural na agricultura familiar, p. 135.
} 
trimônio sociocultural" da agricultura familiar - estão combinados em formas de saber específico, transmitido por gerações sucessivas e que serve de base para o enfrentamento - vitorioso ou não - da precariedade e da instabilidade da estrutura rural. É este saber que fundamenta a complementação e a articulação entre a atividade mercantil e a de subsistência, sobre a base de uma divisão do trabalho interna da família ou da prática do "princípio da alternatividade", formulado por Garcia ${ }^{46}$. Isso, na prática cria, por exemplo, a distribuição de glebas no seio da família fora de uma lógica rígida de venda ou troca de lotes. À medida que ocorrem reconfigurações na organização social da família, caso das uniões matrimoniais, o núcleo familiar redistribui recursos entre si, orientando-se por valores que partem da necessidade de produzir e sobreviver no mercado, mas centralmente orientados pela ligação afetiva com a terra, manifestos pela manutenção de vínculos comunitários e familiares na distribuição espacial das glebas, pela proximidade para cooperação de esforços no trabalho, convivência diária do núcleo, etc. ${ }^{47}$

\section{AGRICULTURA FAMILIAR, HABITUS E VALORAÇÕES SOBRE A TERRA}

Segundo Bourdieu ${ }^{48}$, a dinâmica no espaço social ocorre pela existência do habitus. O habitus é um conjunto de disposições gerais e transponíveis - socialmente construídas e incorporadas - que fazem com que o conjunto de práticas, uma vez produto de condições sociais semelhantes, adquira um caráter sistemático e, da mesma forma, seja sistematicamente distinto de outras condições sociais.

O habitus permite compreender que o agricultor familiar age racionalmente, realizando práticas que reproduzem e transformam as estruturas sociais do espaço social em que se inse- re. Sua racionalidade não é um simples produto de uma razão autoconsciente (capaz de pôr de forma unívoca seus fins e meios, com clara delimitação de valores só econômicos ou somente jurídicos), mas consiste na operação prática do habitus, isto é, de esquemas geradores de classificações e de práticas classificáveis que funcionam na prática sem chegar à representação explícita, e que são o produto da incorporação, sob a forma de disposições, de uma posição diferencial no espaço social. ${ }^{49}$

Assim, a partir de peculiaridades (em especial a racionalidade que ultrapassa o pacto capital-terra, criando novas visões sobre o que seja desenvolvimento econômico, social e político), a dinâmica da agricultura familiar pode ser compreendida à luz da concepção de "habitus", enquanto uma subjetividade socializada ${ }^{50}$, na qual:

[...] os agentes sociais determinam ativamente, por intermédio de categorias de percepção e de apreciação social e historicamente constituídas, a situação que os determina. Podemos dizer até que os agentes sociais são determinados somente e na medida em que eles se determinam; mas as categorias de percepção e de apreciação, que são o princípio desta (auto)determinação, são elas mesmas, em grande parte, determinadas pelas condições econômicas e sociais de sua constituiçãa ${ }^{51}$

Portanto, haveria práticas nas quais e pelas quais os agentes reagem e adaptam-se desencadeando "processos de construção de representações e identidades" 52 . Contudo, essa trajetória é multidirecional, pois não guarda total coerência com a racionalidade econômica ou jurídica. Nela estão inseridos elementos de percepção do agricultor familiar, oriundos do "processo de apropriação que não se deu em um vazio social e político, nem foi resultado de uma classificação estabelecida por setores ou teóricos" ${ }^{\prime 3}$.

Esse "apropriar e perceber" se dá por oposição e diálogo, convergência e divergência, entre

\footnotetext{
${ }^{46}$ GARCIA JR., A. Sul: O caminho do roçado: estratégias de reprodução camponesa e transformação social. Rio de Janeiro: Marco Zero, Brasília: CNPq, 1989. p. $42-50$.

${ }^{47}$ WANDERLEY, M. N. B. Raízes históricas do campesinato brasileiro. In: TEDESCO, João Carlos (Org.). Agricultura familiar: realidades e perspectivas, p. 02.

${ }^{48}$ BOURDIEU, P. Razões práticas: sobre a teoria da ação. Campinas: Papirus, 2008. p. 162-164.

${ }^{49}$ CATANI, A. M. Espaço social e espaço simbólico: introdução a uma topologia social. Perspectiva. Florianópolis, v. 20, p. 107-120, 2002, p. 111

${ }^{50}$ BOURDIEU, P. Pierre Bourdieu avec Löic Wacquant: réponses. Paris: Seuil, 1992. p. 101.

${ }^{51}$ BOURDIEU, P. Pierre Bourdieu avec Löic Wacquant: réponses, p. 111.

${ }^{52}$ SAUER, S. Agricultura familiar versus agronegócio: a dinâmica sociopolítica do campo brasileiro, p. 13.

${ }^{53}$ SAUER, S. Agricultura familiar versus agronegócio: a dinâmica sociopolítica do campo brasileiro, p. 15.
} 
realidade exterior e realidades individuais. Significa a troca recíproca entre o mundo objetivo (da demanda, da oferta e das específicas condições de formação de preço) e o mundo subjetivo da categoria social (visão de mundo). Os agricultores familiares, nesse contexto, são sujeitos e produtos da história, das lutas sociais e das experiências individuais acumuladas. ${ }^{54}$

Esses aspectos teóricos foram observados em alguns trabalhos de campo, a exemplo da formação dos arrendamentos rurais. ${ }^{55}$ Nesse sentido, a dinâmica do habitus na formação de contratos agrários foi investigada a partir das percepções da categoria social acerca da prática de arrendar. Os resultados obtidos, com base em casos do sudoeste goiano, reforçam a tese da heterogeneidade e regionalidade dos arrendamentos rurais na agricultura familiar. A prática contratual foi identificada como fruto de uma combinação reflexiva e multidirecional de fatores que culminam em estratégias que privilegiam o acesso direto à terra pelo direito de propriedade, em detrimento dos arrendamentos rurais. Porém, essas fronteiras não são rígidas, pois são recorrentes as formas alternativas de acesso: contratos atípicos, garantias extrajurídicas e concentração da prática no seio da própria categoria, além de referências discursivas à terra como algo além do comércio, mas identificada como lugar de vida, de trabalho e de interação da família. ${ }^{56}$

Portanto, manifestam-se decisões calcadas em formas de agir e de viver que evidenciam "uma manha", ou ainda, "uma infinidade de esquemas particulares diretamente aplicados a situações particulares" ${ }^{\prime 2}$. Daí a importância de se compreender a prática do arrendamento rural a partir de um contexto de percepção, isto é, inserida na realidade da agricultura familiar, onde as decisões se dão para e por formas de agir e de pensar norteadas pelas ligações afetivas com a terra e pelos vínculos familiares do trabalho. ${ }^{58}$

Opera-se, assim, um sistema constituído de disposições estruturadas no social e estruturantes nas mentes. Essa forma de interpretar o conceito remete a uma análise relacional que enfatiza o caráter de interdependência entre o indivíduo e sua categoria social, considerando um sistema continuamente aberto e constantemente sujeito a novas experiências. ${ }^{59}$

\section{CONCLUSÃO}

A conservação e a transmissão de um patrimônio sociocultural constitui um modelo original, constitucionalmente protegido, que exerce "um papel fundamental no modo de funcionamento da agricultura familiar" 60 . Da centralidade da família, como portadora do esforço de trabalho e detentora da propriedade, tanto quanto, definidora das necessidades de consumo, decorre a importância que assume a evolução de sua composição ${ }^{61}$ como elemento chave do próprio processo de transformação interna da unidade família/estabelecimento.

As valorações acerca da relação de trabalho, do grupamento afetivo e da visão da terra como lar são racionalidades adicionais, consideradas pelo agricultor familiar no momento de decidir, organizar e produzir. Ele centraliza sua decisão em elementos para além do lucro, da renda ou da segurança da propriedade - fatores que evidenciam visões diferentes do modelo de desenvolvimento (anterior à Constituição Federal de 1988) e proposto a partir da Revolução Verde (na década de 1960), focalizada na concentração de terras, no capital e na informação, de maneira excludente. ${ }^{62}$

\footnotetext{
${ }^{54}$ CASTRO, L. F. P. Dimensões e lógicas do arrendamento rural na agricultura familiar, p. 75.

${ }^{55}$ CASTRO, L. F. P. Dimensões e lógicas do arrendamento rural na agricultura familiar, Capítulo 02. p. 62.

${ }^{56}$ CASTRO, L. F. P. Arrendamentos rurais na agricultura familiar: habitus, direito e acesso à terra. Revista Científica Semana Acadêmica, Fortaleza, CE, n. 77, v. 1, ano MMXV, dez. 2015, p. 01-15.

${ }^{57}$ BOURDIEU, P. A economia das trocas simbólicas. 6. ed. São Paulo: Perspectiva, 2009. p. 208-209.

${ }^{58}$ CASTRO, L. F. P.; SAUER, S. A problemática e as condicionantes dos arrendamentos rurais na agricultura familiar. Anais... $50^{\circ}$ Congresso da SOBER, Espírito Santo: Vitória, 2012. p. 13.

${ }_{59}^{5}$ SETTON, M. A teoria do habitus em Pierre Bourdieu: uma leitura contemporânea. Revista Brasileira de Educação. São Paulo, n. 20. maio/jun./jul./ago. 2002. p. 63.

${ }^{60}$ LAMARCHE, Hugues. (Coord.). L'agriculture familiale. 1. Une réalité polymorphe. Paris: L'Harmattan, 1993. p. 13.

${ }^{61}$ WANDERLEY, M. N. B. Raízes históricas do campesinato brasileiro. In: TEDESCO, João Carlos (Org.). Agricultura familiar: realidades e perspectivas, p. 05 .
} 
Por esse caminho, as concepções de mundo são produtos do sujeito, mas também de um agregado de situações provenientes de sua categoria social, ao longo de todo um trajeto histórico. Essas relações podem ser interpretadas a partir da dinâmica de um habitus no espaço social $^{63}$ em que estão inseridos os capitais de uma categoria social. Esse capital não é somente econômico, mas inclui o patrimônio simbólico, cultural e social dos grupos, que se define segundo o capital que possuem. ${ }^{64}$ Assim, argumentos puramente econômicos (renda da terra) ou argumentos somente jurídicos (segurança ou insegurança do direito de propriedade) não são suficientes para compreender os desafios do "desenvolvimento" rural se considerarmos as visões de mundo peculiares dos agricultores familiares - especialmente no que tange ao acesso à terra, valorada reflexamente como lugar de vida, de cidadania e de direitos fundamentais.

Esse "apropriar e perceber" se dá por oposição e diálogo entre realidade exterior e realidades individuais, que encontram na Constituição Federal de 1988 elementos de legitimação da diversidade cultural na relação do agricultor familiar com a terra. Os princípios da dignidade humana e da função social reafirmam, na atual ordem constitucional, os agricultores familiares como sujeitos e produtos da história, das lutas sociais e das experiências acumuladas.

\section{REFERÊNCIAS}

BALESTRO, M. V.; MARINHO, D. N. C.; WALTER, M. I. Seguro-desemprego no Brasil: a possibilidade de combinar proteção social e melhor funcionamento do mercado de trabalho. Sociedade e Estado. Brasília: UnB. Impresso, 2011.

BOURDIEU, P. Sociologia. (Organizador Renato Ortiz). São Paulo: Ática, 1983.

Espaço social e gênese de classes. In:
1989.

(Ed.). O poder simbólico. Lisboa: Difel,

. O poder simbólico. Lisboa: Difel, 1989.

. Pierre Bourdieu avec Löic Wacquant: réponses. Paris: Seuil, 1992.

- A distinção: crítica social do julgamento. São Paulo: Edusp, Zouk, 2008.

Razões práticas: sobre a teoria da ação.

Campinas: Papirus, 2008.

A economia das trocas simbólicas. 6. ed. São Paulo: Perspectiva, 2009.

BRASIL. Constituição da República Federativa do Brasil de 1988. Disponível em: <http://www.planalto.gov.br/ccivil_03/constituicao/ConstituicaoCompilado.htm>. Acesso em: 19 de jan. 2016.

BRASIL. Lei n. 11.326, de 24 de julho de 2006. Estabelece as diretrizes para a formulação da Política Nacional da Agricultura Familiar e Empreendimentos Familiares Rurais. Disponível em: <http://www.planalto.gov.br/ccivil_03/_ ato2004-2006/2006/lei/111326.htm>. Acesso em: 19 jan. 2016.

CASTRO, L. F. P. Dimensões e lógicas do arrendamento rural na agricultura familiar. 2013. Dissertação (Mestrado em Agronegócios) - Universidade de Brasília, Brasília, 2013.

Arrendamentos rurais na agricultura familiar: habitus, direito e acesso à terra. Revista Científica Semana Acadêmica, Fortaleza, CE, n. 77, v. 1, ano MMXV, p. 1-15, dez. 2015.

; SAUER, S. A problemática e as condicionantes dos arrendamentos rurais na agricultura familiar. Anais... 50 $0^{\circ}$ Congresso da SOBER, Espírito Santo, Vitória, 2012.

\footnotetext{
${ }^{62}$ CASTRO, L. F. P. Dimensões e lógicas do arrendamento rural na agricultura familiar, p. 29.

${ }^{63}$ SETTON, M. A teoria do habitus em Pierre Bourdieu: uma leitura contemporânea. Revista Brasileira de Educação. São Paulo, n. 20. maio/jun./jul./ ago. 2002. p. 66.

${ }^{64}$ BOURDIEU, P. Sociologia. (Organizador Renato Ortiz). São Paulo: Ática, 1983. p. 81-90.
} 
CATANI, A. M. Espaço social e espaço simbólico: introdução a uma topologia social. Perspectiva. Florianópolis, v. 20, p. 107-120, 2002, p. 111.

CHAHAD, J. P. Z. Flexibilidade no mercado de trabalho, proteção aos trabalhadores e treinamento vocacional de força de trabalho: a experiência de América Latina e perspectivas (Análise do caso brasileiro). Documento de Proyecto da CEPAL. Santiago: Naciones Unidas, 2009.

CHALITA, M. A. N. Agricultura familiar na citricultura paulista: a reconstituição da trajetória de um conceito. Anais... XLIII Congresso da Sociedade Brasileira de Economia e Sociologia Rural - Instituições, eficiência, gestão e contratos no sistema agroindustrial. São Paulo, Ribeirão Preto, 2005.

COMPARATO, F. K. Direito e deveres em matéria de propriedade. In: STROZAKE, J. J. (Org.). A questão agrária e a justiça. São Paulo: RT, 2000.

COSTABEBER, J.A.; CAPORAL, F.R. Possibilidades alternativas do desenvolvimento rural sustentável. In: VELA, Hugo et al. (Org.). Agricultura familiar. Santa Maria, RS: Ed. da UFSM, 2003.

CUNHA FILHO, F. H. Direitos culturais como direitos fundamentais no ordenamento jurídico brasileiro. Brasília: Brasília Jurídica, 2000.

FURTADO, C. O mito do desenvolvimento econômico. São Paulo: Círculo do Livro, 1974. FURTADO, C. Formação econômica do Brasil. São Paulo: Companhia das Letras, 2007.

GARCIA JR., A. Sul: O caminho do roçado: estratégias de reprodução camponesa e transformação social. Rio de Janeiro: Marco Zero, Brasília: CNPq, 1989.

GEISLER, N. L. Enciclopédia de apologética. São Paulo: Vida, 2002.

GIRARDI, E. P. Proposição teóricometodológica de uma cartografia geográfica crítica e sua aplicação no desenvolvimento do Atlas da Questão
Agrária Brasileira. Tese (Doutorado em Geografia) - Faculdade de Ciências e Tecnologia, Universidade Estadual Paulista, Presidente Prudente. 2008.

GIRARDI, E. P. Atlas da Questão Agrária Brasileira. Disponível em: <http://www2.fct.unesp.br/ nera/atlas/questao_agraria.htm>. Acesso em: 19 jan. 2016.

GÓMEZ, J. R. M. Desenvolvimento em (des) construção: narrativas escalares sobre desenvolvimento territorial rural. Presidente Prudente, 2006. Tese (Doutorado em Geografia) - Faculdade de Ciências e Tecnologia, Universidade Estadual Paulista, 2006.

HALL, P. A.; GINGERICH, D. W. Varieties of capitalism and institutional complementarities in the macroeconomy: an empirical analysis. Cologne: Max Planck Institute for the Study of Societies MPIFG Discussion Paper, 2004. Disponível em: <http://www.mpifg.de/pu/mpifg_dp/dp045.pdf $>$. Acesso em: 20 jan. 2016.

INSTITUTO BRASILEIRO DE GEOGRAFIA E ESTATÍsTICA. Censo Agropecuário 2006: Brasil, Grandes Regiões e Unidades da Federação. Rio de Janeiro, RJ: IBGE. 2007. Disponível em: <http://ibge.gov.br/home/estatistica/economia/ agropecuaria/censoagro/2006_segunda_apuracao/default.shtm>. Acesso em: 15 set. 2014.

INSTITUTO BRASILEIRO DE GEOGRAFIA E ESTATÍSTICA. Séries Estatísticas \& Séries Históricas. Censos Agropecuários (1920 a 1995/96). Rio de Janeiro, RJ: IBGE. 2013. Disponível em: $<$ http:www.ibge.gov.br/series_estatisticas/subtema.php?idsubtema $=100>$. Acesso em: 15 set. 2014.

INSTITUTO NACIONAL DE COLONIZAÇÃO E REFORMA AGRÁRIA/FOOD AND AGRICULTURE ORGANIZATION OF THE UNITED NATIONS. Perfil da Agricultura Familiar no Brasil: dossiê estatístico. MDA: Brasília, 1996.

KAGEYAMA, A et al. O novo padrão agríco- 
la brasileiro: do complexo rural aos complexos agroindustriais. In: DELGADO, G. C.; GASQUES, J. G.; VILLA VERDE, C. M. (Orgs.) Agricultura e políticas públicas. Brasília: IPEA, 1990. p. 113-223.

LAMARCHE, Hugues. (Coord.). Lagriculture familiale. 1. Une réalité polymorphe. Paris: L'Harmattan, 1993.

1994.

.Du mythe à la réalité. Paris: L'Harmattan,

LIMA, R. A. M. Direito agrário. Rio de Janeiro: Renovar, 1994.

MIRANDA, A. G. O instituto jurídico da posse agrária. Belém: Cejup, 1992.

MORAES, A. Direitos humanos fundamentais: teoria geral, comentários aos arts. $1^{\circ}$ a $5^{\circ}$ da Constituição da República Federativa do Brasil, doutrina e jurisprudência. 6. ed. São Paulo: Atlas, 2005.

NEVES, D. P. Agricultura familiar: questões metodológicas. Revista Reforma Agrária. Campinas,SP, v. 25, n, 2, p. 21-37. 1995.

PEREIRA, R. P. C. A teoria da função social da propriedade rural e seus reflexos na acepção clássica de propriedade. In: STROZAKE, Juvelino Hosé (Org.). A questão agrária e a justiça. São Paulo: RT, 2000.

SARLET, I. W. Dignidade da pessoa humana e direitos fundamentais na Constituição Federal de 1988. Porto Alegre: Livraria do Advogado, 2001.

A eficácia dos direitos fundamentais. 7. ed. rev. atual. e ampl. Porto Alegre: Livraria do Advogado, 2007.

SAUER, S. A luta pela terra e a reinvenção do rural. Anais... XI Congresso de Sociologia, São Paulo, Campinas. 2003.

Agricultura familiar versus agronegócio: a dinâmica sociopolítica do campo brasileiro. Brasília, DF: Embrapa Informação Tecnológica, 2008.

Terra e modernidade: a reinvenção do campo brasileiro. São Paulo: Expressão Popular, 2010.

SETTON, M. A teoria do habitus em Pierre Bourdieu: uma leitura contemporânea. Revista Brasileira de Educação. São Paulo, n. 20. maio/ jun./jul./ago. 2002.

TEDESCO, J. C. Agricultura familiar: realidades e perspectivas. Passo Fundo, RS: Ed. da UPF, 2001.

Raízes históricas do campesinato brasileiro. In: MOTA, D. M. da; TAVARES, E. D.; IVO, W. M. P. de M. (Org.). Agricultura familiar em debate. Sergipe: Aracaju, EMBRAPA-CPATC, 1997

WANDERLEY, M. N. B. Raízes históricas do campesinato brasileiro. In: TEDESCO, João Carlos (Org.). Agricultura familiar: realidades e perspectivas. 1. ed. Passo Fundo, RS: Universidade de Passo Fundo, 1999.

WANDERLEY, M. N. B. Reencontro com o Nordeste: Itinerários de pesquisa e construção do campo intelectual dos estudos rurais. Estudos de Sociologia, Recife, v. S, n. 1, p. 1-132, 1999. Disponível em: <http://www.revista.ufpe.br/revsocio/index.php/revista/article/view/306>. Acesso em: 19 jan. 2016.

A ruralidade no Brasil moderno: por um pacto social pelo desenvolvimento rural. In: GIARRACCA (Coord.). Una nueva ruralidad en América Latina? Buenos Aires: CLACSO, 2001.

Agricultura familiar e campesinato: rupturas e continuidades. In: (Org.). $O$ mundo rural como espaço de vida: reflexões sobre a propriedade da terra, agricultura familiar e ruralidade. Porto Alegre. Ed. da UFRGS, 2009. p. 185-200.

. O agricultor familiar no Brasil: um ator 
social da construção do futuro. Revista Agriculturas - Experiências em Agroecologia. Rio de Janeiro, AS-PTA, p. 33-45, 2009.

O mundo rural brasileiro: acesso a bens e serviços e integração campo-cidade. Estudos Sociedade e Agricultura e Sociedade. Rio de Janeiro, UFRJ, v.17, n. 1, 2009.

Recebido: 25/10/2015

Aprovado: 05/12/2015 